\title{
Reassessment of Remaining Strength of Subsea Corroded Pipeline using Bayesian Updating
}

\author{
Zafarullah Nizamani ${ }^{1, a^{*}}$ and Zahiraniza Mustaffa ${ }^{2, b}$ \\ ${ }^{1}$ Department of Environmental Engineering, Faculty of Engineering and Green Technology, \\ Universiti Tunku Abdul Rahman, Malaysia. \\ ${ }^{2}$ Department of Civil Engineering, Universiti Teknologi PETRONAS, Malaysia. \\ azafarullah@utar.edu.my bahiraniza@petronas.com.my
}

Keywords: corrosion, subsea pipeline, remaining strength, burst test, Bayesian updating

\begin{abstract}
System strength evaluation of subsea pipeline, which has already completed its design life, is an important issue to deal with especially when hydrocarbon is the material to be transported. The remaining strength of pipeline in terms of probability of failure can be determined using assessment of maximum operating pressure and its capacity by using burst test results. Monte Carlo simulation is used to find probability of failure and then with burst test results the existing probability of failure can be updated using Bayesian updating technique.
\end{abstract}

\section{Introduction}

Pipeline failure due to corrosion depends on quantity of corrosion (defect size) and material yield stress. Internal and external corrosion are collectively one of the most important causes of failure of pipeline. Re-assessment of strength of corroded subsea pipeline is an important issue due to risk involved with transportation and distribution of hydrocarbon. The reevaluation of thickness of pipe defect size after ultra-sonic and magnetic flux tests is used to decide the fitness of strength. The main methods for evaluation of remaining strength are based on three codes which are DNV-RPF101, B31G by ASME based on NG 18 Equation, RSTRENG by Shell. In this paper two codes of practice DNV and $\mathrm{B} 31 \mathrm{G}$ are used to evaluate the updated probability of failure.

\section{Background}

Corrosion was major cause of pipe failures i.e. 18\% of significant incidents from 1988-2008 [1]. External corrosion hydrocarbon pipes is caused by sea water and for internal it is hydrogen sulfide, sodium chloride and carbon dioxide. The experimental and numerical data is used to asses and determine remaining life of pipelines using risk analysis. The risk analysis is made to evaluate the real time condition of pipeline after detecting the defects in it. It is named as forecast of associated hypothetical risks assessment [2]. The scarcity of empirical data, uncertainty of mathematical model and expert opinion play significant role for risk analysis [2]. Bayesian updating is used for determination of uncertainty during risk analysis modeling. When failure probabilities are considered following requirements are needed to be fulfilled i.e. identical components, same operating and loading conditions and independent failures [3]. In case when above conditions are not met like unique configuration of pipelines and pressure vessels Bayesian updating is used. The probability of failure can be evaluated by Monte Carlo simulation as shown in Equation (1)

$$
P_{f}=\frac{N_{f}}{N}
$$

Where, $N_{f}=$ number of failures, $N=$ total number of simulation.

Survival probability of platform $\left(\mathrm{P}_{\mathrm{s}}\right)$, as shown in Equation (2),

$$
\mathrm{P}_{\mathrm{s}}=\frac{\text { Number of Survival }}{\text { Total Number of Simulations }}
$$


When Pf is evaluated given that Ps is also known then we can find the updated probability of failure $\left(\mathrm{P}_{\mathrm{uf}}\right)$ based on Equation (3). Failure probability has already been found using Equation (1). The new updated probability of failure was given by Equation (3),

$$
\mathrm{P}_{\mathrm{uf}}=\mathrm{P}(\mathrm{g}<0 \mid \mathrm{S}>0)
$$

$\mathrm{P}(\mathrm{g}<0)=$ Probability of failure of limit state function, $P(S>0)=$ Probability of survival of limit state function

Thus updated probability of failure $\left(\mathrm{P}_{\mathrm{uf}}\right)$ can be shown by Equations (4-5),

$$
\begin{aligned}
& \mathrm{P}_{\mathrm{uf}}=\frac{\mathrm{P}[\mathrm{g}(\mathrm{x})<0 \cap S>0]}{\mathrm{P}[\mathrm{S}>0]} \\
& \mathrm{P}_{\mathrm{Uf}}=\mathrm{P}(\mathrm{g} \mid \mathrm{S}) \mathrm{P}(\mathrm{S})
\end{aligned}
$$

\section{Methodology}

Results from an experimental study were made available for this study for a sample taken from $6.9 \mathrm{~km}$ pipeline carrying wet and semi processed crude oil between two Jacket platforms in offshore Malaysia. The sample was taken at the recommendation of strength evaluator's recommendation that due to corrosion effects pipe's strength has deteriorated and it should be replaced to avoid a pipe failure. About $750 \mathrm{~m}$ of pipe was replaced in 2008. Pipeline nominal diameter was $274 \mathrm{~mm}$ and nominal wall thickness was $14 \mathrm{~mm}$. Once this corroded pipe was removed $2 \mathrm{~m}$ sections were selected for burst testing. The material was carbon steel and the grade was API 5L-X52. Design code used for pipeline was ASME B31G. According to this code metal loss of $80 \%$ of characteristic wall thickness shall not be considered and metal loss of maximum of $10 \%$ of characteristic wall thickness is not limited to allowable strength [4]. The operating temperature at inlet was $55{ }^{\circ} \mathrm{C}$ and at outlet was $30^{\circ} \mathrm{C}$. The minimum water depth was in range of $65-67 \mathrm{~m}$. Pipeline was fabricated and installed in 1982 for a design life of 20 years which expired in 2002. The original maximum allowable operating pressure was 93 bars, which has been derated two times i.e. 40 and 28 bars. Two types of results based on experimental study are available i.e. Magnetic Flux Leakage (MFL) and Ultra Sonic test (UT). Burst test was carried out for longitudinally real and artificial corrosion defects in pipe subject to internal pressure. The artificial defects were made by using machine pits and flat bottom defects. The real corrosion has always defects with irregular profile. Corrosion in pipeline is difficult to characterize most of time it will have irregular depth profile. Another issue is that it extends in irregular profile in length and in its circumference. These defects may be single or group of contiguous defects separated by uncorroded material. In this research two codes were used, for evaluating remaining strength of pipeline, to compare the probability of failure.

For probability of failure two types of equations are important i.e. actual capacity and maximum allowable operating pressure equation. Capacity equation is used to predict the capacity of corroded pipeline for given area, material properties, defect shape and size. This equation will give us actual resistance of pipe. The other is called acceptance equation which gives safe allowable operational pressure. This will provide the pipeline maximum allowable operating pressure with corrosion defects.

B31G Code. No model uncertainty factor was available for B31G code Equation therefore it was evaluated used Monte Carlo simulation. Equation 10 was used to find model uncertainty. Kolmogorov-Smirnov and Anderson Darling tests were used to find the best fit which showed it to be normal distribution with mean of 1.07 and standard deviation of 0.1 . Performance function for finding the probability of failure for B31G code is shown by Equation (6), 
$g=\left\{1.1 F * T \frac{(\text { SMYS }+69 \mathrm{MPa}) x 2 x t}{D}\left[\frac{1-0.85 x \frac{d}{t}}{1-0.85 x \frac{d}{t} \times \frac{1}{M_{2}}}\right] x X_{m}\right\}-\left\{1.1\left(1-\frac{d}{t}\right)\left[\operatorname{SMYS} x F x \operatorname{Tr} \frac{2 x t}{D}\right]\right\}$

DNV-RP-F101 code. Performance function for finding the probability of failure in DNV RP-F101 code is shown by Equation (7),where $\mathrm{P}_{\text {int }}$ is given by Gumbel distribution with its mean and standard deviation are given in Table 6.

$$
\mathrm{g}=1.05 \times \frac{2 t \sigma_{u}}{(D-t)} \frac{(1-(d / t))}{\left(1-\frac{(d / t)}{\sqrt{1+0.31\left(\frac{L}{\sqrt{D t}}\right)^{2}}}\right)}-\gamma_{m} \frac{2 t \operatorname{sMTS} s}{(D-t)} \frac{\left(1-\gamma_{d}(d / t)^{*}\right)}{\left(1-\frac{\gamma_{d}(d / t)^{*}}{Q}\right)}
$$

Bayesian Updating. Initially probability of failure was determined using capacity and maximum allowable operating pressure equation. Then ratio was determined for burst test to MAOP, this ratio was used with MAOP equation to find updated probability of failure. The burst test here worked as proof load on pipeline. Information available through burst test shows that the actual strength is much higher as compared to MAOP.

\section{Result and Discussion}

Four samples with varying thicknesses were selected for burst test as shown in Table 1 . The $d / t$ ratio varied in between 0.33 to 0.43 .

Table 1: Geometrical parameters of corroded pipeline

\begin{tabular}{|c|c|c|c|c|c|c|}
\hline \multirow{2}{*}{$\begin{array}{c}\text { Diameter } \\
(\mathrm{mm})\end{array}$} & \multirow{2}{*}{$\begin{array}{c}\text { SMYS } \\
(\mathrm{MPa})\end{array}$} & \multirow{2}{*}{$\begin{array}{c}\text { SMTS } \\
(\mathrm{MPa})\end{array}$} & \multicolumn{2}{|c|}{$\begin{array}{c}\text { Parameter defect dimensions } \\
(\mathrm{mm})\end{array}$} & $\begin{array}{c}\text { Wall } \\
\text { thickness }(\mathrm{t})\end{array}$ & $\mathrm{d} / \mathrm{t}$ \\
\cline { 4 - 7 } & & & Length $(\mathrm{L})$ & Defect depth $(\mathrm{d})$ & \\
\hline 274.00 & 358 & 455 & 200 & 4.5 & 11.1 & 0.41 \\
\hline 274.00 & 358 & 455 & 250 & 4.0 & 12.0 & 0.33 \\
\hline 274.00 & 358 & 455 & 250 & 5.3 & 12.8 & 0.41 \\
\hline 274.00 & 358 & 455 & 200 & 6.0 & 14.0 & 0.43 \\
\hline
\end{tabular}

Burst test to MAOP ratio was used to increase the loading part for the updating of probability of failure. Comparative effect of two code equations on MAOP and burst test was evaluated. It can be seen that ASME code equation predicts well the burst test results as compared to DNV code. Table 2 shows various ratios of burst test to MAOP for DNV and B31G codes. The acceptable probability of failures for high safety class is $<10^{-5}$, normal $<10^{-4}$ and low is $<10^{-3}$.

Table 2: MAOP and Burst Test results

\begin{tabular}{|l|c|c|c|c|}
\hline \multicolumn{1}{|c|}{ Code } & $\mathrm{d} / \mathrm{t}$ & MAOP (bar) & $\begin{array}{c}\text { Burst Test } \\
\text { Pressure (bar) }\end{array}$ & Burst test/MAOP \\
\hline DNV-RP-F101 & 0.41 & 138.4 & 326.5 & 2.3 \\
\hline ASME B31G & 0.41 & 178.0 & 326.5 & 1.7 \\
\hline DNV-RP-F101 & 0.33 & 190.7 & 294.9 & 1.5 \\
\hline ASME B31G & 0.33 & 204.6 & 294.9 & 1.4 \\
\hline DNV-RP-F101 & 0.41 & 163.1 & 326.5 & 2.0 \\
\hline ASME B31G & 0.41 & 205.4 & 326.5 & 1.6 \\
\hline DNV-RP-F101 & 0.43 & 183.6 & 294.9 & 1.6 \\
\hline ASME B31G & 0.43 & 225.7 & 294.9 & 1.3 \\
\hline
\end{tabular}


The first case here was with thickness of $11.1 \mathrm{~mm}$ and $\mathrm{d} / \mathrm{t}$ ratio of 0.41 as shown in Figure 1 . The ratio of burst test to MAOP came out to be 2.3 and 1.7 for DNV and B31G code respectively. Here the probability of failure was $2.1 \times 10^{-3}$ and $2.0 \times 10^{-3}$. It can be seen there is not much difference in actual probability of failure for both codes. This probability of failure is not sufficient as per Table 6 for normal risk structure. Therefore updating of probability of failure using Bayesian updating was carried out for both cases. The DNV gave probability of failure of $6.14 \times 10^{-4}$ and B31G gave $6.96 \times 10^{-5}$. This shows that the pipeline has actual failure probability much lower than the actual anticipated. The higher updated probability of failure of $\mathrm{B} 31 \mathrm{G}$ is due to its sensitiveness to $\mathrm{d} / \mathrm{t}$ ratio as compared to DNV code.

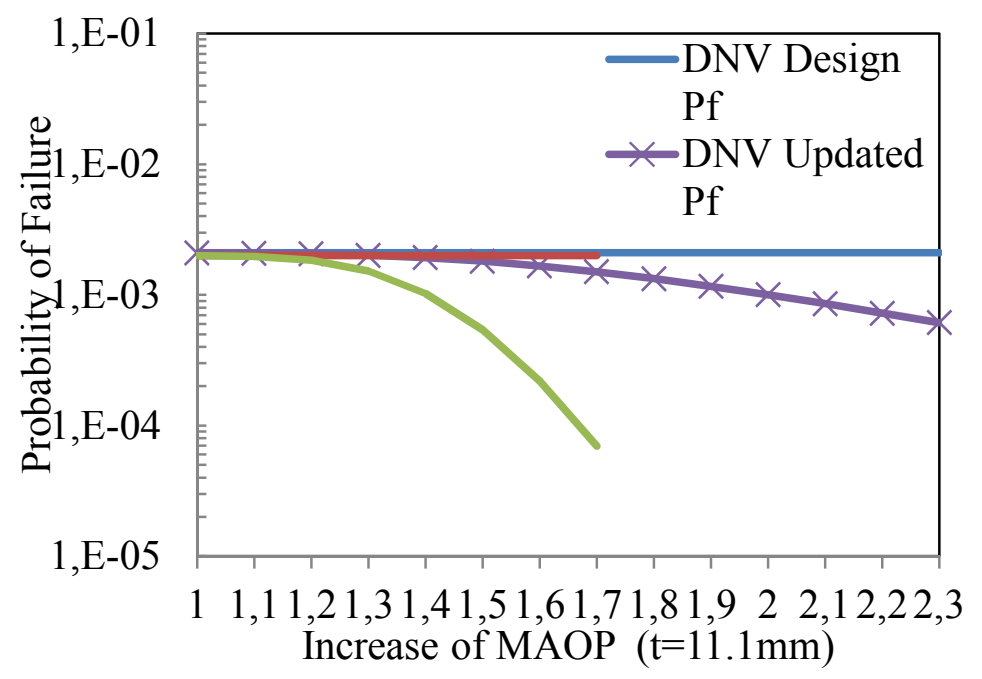

Figure 1: Probability of failure_MAOP \& Capacity

Figure 2 shows the member with thickness of $12 \mathrm{~mm}$ and $\mathrm{d} / \mathrm{t}$ ratio of 0.33 . The ratio of burst test to MAOP came out to be 1.5 and 1.4 for DNV and B31G code respectively. Here the probability of failure was $3.2 \times 10^{-3}$ and $5.3 \times 10^{-3}$. Updating of probability of failure using Bayesian updating was carried out for both cases. The DNV gave probability of failure of $2.35 \times 10^{-3}$ and B31G gave $1.8 \times 10^{-3}$. Here higher probability of failure was achieved due to low $\mathrm{d} / \mathrm{t}$ ratio.

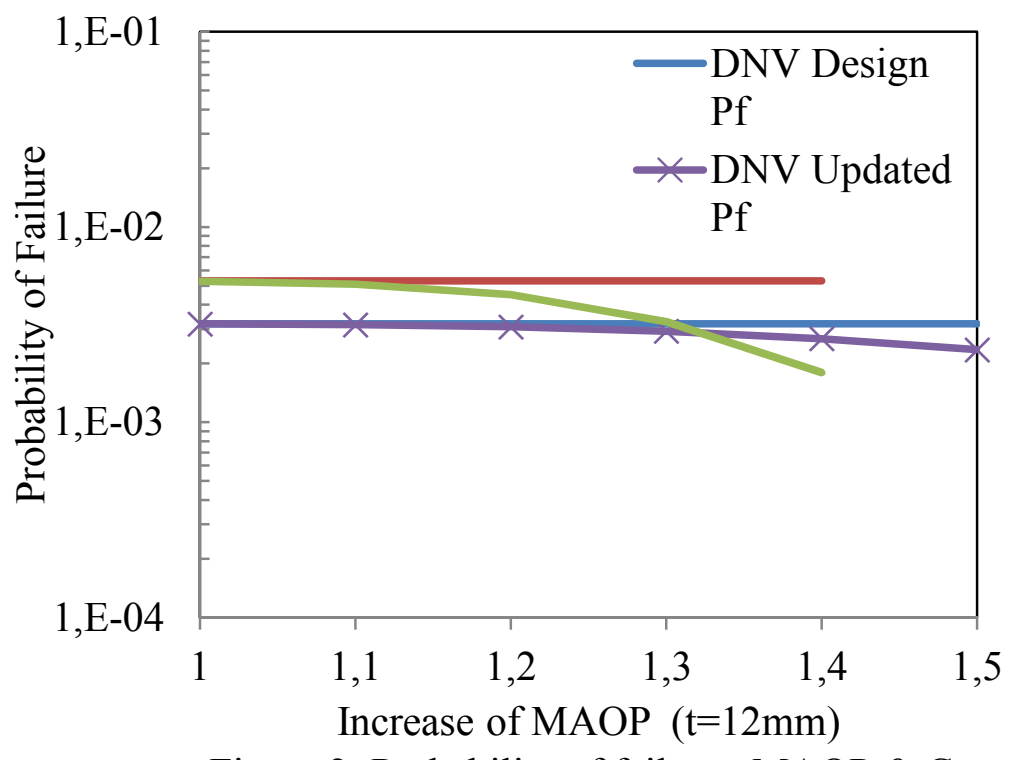

Figure 2: Probability of failure _MAOP \& Capacity 


\section{Conclusions}

Two codes were used in this study to evaluate the updated probability of failure. The main conclusions are listed as below:

1) Model uncertainty factor for B31G code was determined using normal distribution for thickness as suggested by DNV code

2) B31G code predicted well with actual burst test though its sensitivity with $\mathrm{d} / \mathrm{t}$ ratio was very high. Probability of failure using capacity and MAOP gave high probability of failure. This cannot be used to given extension of life. The updated probability of failure gave low probability of failure and thus extension of life can be given after using Bayesian updating.

3) DNV code was not found to be sensitive to $d / t$ ratio. Probability of failure using capacity and MAOP gave high value. This cannot be used to given extension of life. The updated probability of failure gave low probability of failures and thus extension of life can be given after using Bayesian updating.

\section{Abbreviations.}

\begin{tabular}{|c|c|c|}
\hline $\mathrm{D}$ & Nominal outside diameter of pipe & \begin{tabular}{l|l}
$\gamma_{m}$ & Safety factor for model prediction \\
\end{tabular} \\
\hline $\mathrm{t}$ & Nominal wall thickness of pipe & \begin{tabular}{l|l} 
d & Maximum depth of corroded area
\end{tabular} \\
\hline$S t D[d / t]$ & Standard deviation of measured $(\mathrm{d} / \mathrm{t})$ ratio & \begin{tabular}{c|c}
$\sigma_{u}$ & Ultimate Tensile Strength $\left(\mathrm{N} / \mathrm{mm}^{2}\right)$
\end{tabular} \\
\hline $\mathrm{T}$ & $\begin{array}{l}\text { Temperature de-rating factor (if none } \\
\text { listed, } \mathrm{T}=1.0 \text { ) }\end{array}$ & $\begin{array}{ll}\text { F } & \text { (appropriate design factor) (Normally } \\
\text { equal to } 0.72 \text { ) }\end{array}$ \\
\hline $\begin{array}{l}\text { SMYS } \\
(\mathrm{T})\end{array}$ & $\begin{array}{l}\text { Specified minimum yield stress at } \\
\text { temperature } \mathrm{T}\end{array}$ & $\gamma_{d}$ Safety factor for corrosion depth \\
\hline$Q$ & Length correction factor & $\begin{array}{ll}\mathrm{L} & \text { Corroded length } \\
\end{array}$ \\
\hline$M_{2}$ & $\begin{array}{l}\text { Folias (bulging) factor (accounting for } \\
\text { effect of stress concentration at notch) } \\
\text { (Bulging stress magnification factor) }\end{array}$ & \begin{tabular}{l|l} 
A & $\begin{array}{l}\text { Projected corroded area (Local area of } \\
\text { metal loss in longitudinal plane) } \\
\left(\frac{2}{3} d x L\right)\end{array}$ \\
\end{tabular} \\
\hline
\end{tabular}

\section{References}

[1] R. R. Fessler, Pipeline Corrosion, Michael Baker Jr., Inc.2008.

[2] S. Ferson, Bayesian methods in risk assessment, Service Environnement \& Procédés, USA2004.

[3] M. H. Faber, Basics of Structural Reliability, Swiss Federal Institute of Technology ETH, Switzerland2001.

[4] Bin Ma, Jian Shuai, Junqiang Wang, Kejiang Han Analysis on the Latest Assessment Criteria of ASME B31G-2009 for the Remaining Strength of Corroded Pipelines, Journal of Failure Analysis and Prevention, vol. 11, pp. 666-671, 2011. 